\title{
A PERSONAL NOTE TO UNDERGRADUATES
}

Yanomami: The Fierce Controversy and What We Can Learn from It deals with one of the most explosive controversies in the history of anthropology. It has all sorts of ideas that will intrigue you, that will challenge you, that will make you think - just what you want from your college education. But it is important to see the forest through the trees in this controversy, to grasp the bigger picture rather than getting lost in a mass of details. What follows are some reading techniques that you can apply not only to this book but to scores of books in other classes. These techniques will be especially useful in reading part 2.

\section{Deciding on a Reading Strategy}

Selecting an effective reading strategy is probably the most important decision you make when you begin a book. Different reading materials require different strategies. (One does not read newspapers, for example, the same way one reads Shakespeare.) Choosing an effective strategy depends not only on the book's subject matter but also on how you are to be tested on it. Multiple-choice exams require a different reading strategy than essay exams.

\section{Focusing on Broad Themes When Reading for Essay Exams}

Details are important in relation to the book's overall thesis but less important in and of themselves. To do well on an essay exam, you should know a book's argument and how it is constructed. I refer to this reading strategy as "searching for meaning."

\section{Searching for Meaning}

Doing well on an essay exam requires more than passively reading words on a page. You must think about what you are reading and, like a detective, actively put together various pieces of information to grasp the author's meaning. Boiled down to its basics, "searching for meaning" involves four steps:

Using chapter headings and subheadings to gain an overview. Before reading a chapter, skim through it, focusing on the headings and subheadings to get an 
overview of what the chapter is about. The section titles of this volume, especially in chapters 8, 9, and Io, are written with this in mind. Thus, for example, a section in Ray Hames's contribution in chapter 8 is entitled "Is the Critique of Chagnon Justified?" You know, just by looking at the heading, what Hames is going to discuss.

Reading by paragraphs. One of the most effective ways to read chapters in a book such as this is to read "by paragraphs." This technique allows you to concentrate on a chapter's main ideas. Reading by paragraphs means focusing on the key sentence in each paragraph, that is, the sentence that enhances the author's overall argument in the chapter.

The key sentence tends to be either the first, second, or last sentence in a paragraph. On first reading, you will usually discover it is best to put a paragraph's details to one side - not to ignore them but to focus on the central issue raised by the chapter as a whole. Later on, after you understand the chapter's overall argument, you have the option of going back through the chapter and noting these details.

Move quickly from paragraph to paragraph, focusing on the key sentence in each paragraph. When you reach the end of a section (that is, a new heading), pause to see if you have grasped the main idea of the section. You might summarize it in a sentence or two.

The object of reading by paragraphs is not simply to get through a chapter quickly. Rather, it is to distinguish details from main themes. It allows you to comprehend the main points of an author's argument.

Reading slowly does not necessarily improve comprehension. It may, in fact, decrease comprehension. The slower you read, the more details you become mired in and the less likely you are to comprehend the chapter as a whole. Also you do not need to know the meaning of each and every word in a paragraph or to recognize each and every citation to grasp the idea of a chapter. Many terms and citations can be understood in a general way from the context. Key terms may be looked up in a dictionary later. Terms or citations that relate to minor points may be set aside during a first reading.

Reconstructing an author's argument. After finishing a chapter, review the chapter's headings and subheadings again. Having read the chapter, you can now reflect on the author's argument: (I) why the chapter moves in a certain direction; (2) what points are central (and which are tangential) to the chapter's themes; and (3) why one point follows another.

Assessing the author's argument. After reading a book, assess the author's argument. Understanding what the author intends to say, you are now in a position to decide to what degree the argument makes sense, to what degree it is sup- 
ported by the author's data. Does the author convincingly develop his or her position? Or does the author leave you with unanswered questions?

Instead of conceiving of reading as a passive process - taking in information presented to you - think of reading as an active thinking process. You are searching for meaning from various clues presented in the text. Discovering the clues, making sense of them, is an intellectually stimulating process. 
